Prix Gonstant (Dépòt d'ouvrage). - M. É. GuYÉnot, préparateur à la Sorbonne, dépose, en vue de l'obtention du Prix Constant 1912, un travail sur " Les papilles de la trompe des Lépidoptères " paru dans le Bulletin scientifique de la France et de la Belgique, $7^{\text {e }}$ série, XLVI (1912).

Comité national de Nomenclature entomologique. -- A la demande du Comité national de Nomenclature entomologique, la Société procède à la nomination de trois membres supplémentaires de ce comité. Sont élus : MM. L. Bedel, A. Janet et Ch. Oberthür.

\title{
Observations diverses
}

Rectification synonymique. - MM. K. Jordan et N. C. Rothschild ont décrit dans le dernier fascicule des "Novitates Zoologicae ", vol. XIX, p. 3 כั3 (1912), sous le nom d'Aphrania, un genre nouveau de Cimicide [Hem.] fondé sur une espèce nouvelle provenant de l'Afrique méridionale. Ce nom générique étant déjà préoccupé par Afrania Stål. Hem. Afr. I., p. 81 et 180 (186ä), le $\mathrm{D}^{\mathrm{r}}$ G. DE Horváth propose pour le nouveau genre établi par MM. JoRdan et RothschiLd le nom Aphraniosa, nom. nov.

\section{Gommunications.}

\section{Description d'un Eudicella White [Col. Scarabaeidae] nouveau de I'Afrique Orientale}

par A. Bourgoin.

Eudicella cupreosuturalis, n. sp. - o Caput, pronotum, scutellumque brunneo-ruhra, valde punctata. Elytra viridia, minute punctulata; sutura cupreo-purpurea, nitida. Corpus subtus ad latera obscuro-viride; capite subtus, processu mesosternali, coxis, sulco abdominali, femoribus, tibiis intus tarsisque rubris.

ơ. Tète, pronotum et scutellum d'un rouge de laque brunâtre avec de vagues reflets verts, élytres verts à suture pourpre cuivreux brillant. Front finement et densément ponctué en arrière, grossement et 
éparsement derrière les yeux, avec, en son milieu, une très fine ligne lisse. Espace interoculaire déprimé de chaque còté, convexe au milieu, fortement alutacé, avec de gros points enfoncés, échancré subcirculairement et brusquement abaissé en avant, excepté au milieu qui s'élève en une carène obtuse qui atteint la base de la corne antéro-médiane du clypéus.

Clypéus à bords latéraux parallèles, terminé en avant, au milieu, par une corne assez large a la base, bifurquée en lobes aigus fortement divergents, de chaque côté par une saillie dentiforme relevée. De l'extrémité de chacune de ces saillies part une carène qui se dirige en arrière, puis disparaît près de la carène médiane en formant un angle de $4{ }^{\circ}$ avec le rebord du clypéus. Les deux carènes latérales convergent sous un angle de $90^{\circ}$.

Pronotum très densément couvert, sur toute sa surface, de points irréguliers, plus gros sur les côtés, surtout aux angles antérieurs. Scutellum en triangle isocèle à base égale à la hauteur, finement et densément ponctué sur toute sa surface, avec des points plus gros sur les còtés.

Élytres très densément et linement ponctués avec des points un peu moins fins en lignes peu visibles si ce n'est près de la suture. Suture très brillante d'un pourpré cuivreux à reflets vert-doré, légèrement relevée en arrière. Dessous glabre, sauf aux hanches et aux fémurs antérieurs; saillie mésosternale assez courte, en triangle obtus, avec une dépression vers la suture méso-métasternale; côtés du pectus fortement ponctués, vert-brunâtre sombre ainsi que les côtés de l'abdomen. Dessous de la tète, saillie mésosternale, sillon de l'abdomen, hanches, fémurs, tranche interne des tibias, et tarses d'un rouge de laque peu brillant. Pygidium vert-bleuâtre sombre, finement ponctué.

Longueur (du bord antérieur du pronotum à l'extrémité des élytres) : 27 mill. - Largeur aux épaules : 1õ, mill. ö.

Afrique orientale anglaise, $\mathbf{M}^{\mathrm{t}}$ Kenya, versant ouest, altit. $2.400 \mathrm{~m}$. 1 ๙ $^{x}$ type (Coll. du Muséum de Paris).

Mission Ch. Altuatd et R. Jeannel. 


\section{$2 \mathrm{BHL}$ Biodiversity Heritage Library}

1913. "Description d'un Eudicella White nouveau de l'Afrique orientale." Bulletin de la Société entomologique de France 1913, 131-132. https://doi.org/10.5962/bhl.part.16275.

View This Item Online: https://www.biodiversitylibrary.org/item/36377

DOI: https://doi.org/10.5962/bhl.part.16275

Permalink: https://www.biodiversitylibrary.org/partpdf/16275

\section{Holding Institution}

Smithsonian Libraries

\section{Sponsored by}

Smithsonian

\section{Copyright \& Reuse}

Copyright Status: NOT_IN_COPYRIGHT

This document was created from content at the Biodiversity Heritage Library, the world's largest open access digital library for biodiversity literature and archives. Visit BHL at https://www.biodiversitylibrary.org. 